\title{
Moon mission poses dilemma for scientists
}

Washington. Next Tuesday (25 January) will see the launch from the Vandenberg Air Force Base in California, of the first US mission to the Moon for 20 years. After spending several months photographing the lunar surface, the spacecraft, known as Clementine, will fly back past Earth for a high-speed encounter with the asteroid Geographos in August.

But planetary scientists are in two minds about the implications of their participation in the \$75-million mission, which is being funded jointly by the Department of Defense (DoD) and the National Aeronautics and Space Administration (NASA).

For the gathering of scientific data is a bonus on a trip originally conceived by President Ronald Reagan's Strategic Defense Initiative Office - the body set up to run the 'Star Wars' programme - now scaled down and renamed the Ballistic Missile Defense Organization.

Star Wars required lightweight, 'intelligent' spacecraft capable of hunting down fast-moving objects. As testing such a craft in Earth orbit would breach the Anti-Ballistic Missile (ABM) Treaty, Clementine was born to carry out the tests in outer space.

With the thawing of the Cold War, a group of planetary scientists, led by Eugene Shoemaker of the US Geological Survey, thought they could hitch a ride on board a military mission which had become an open secret. As a result, NASA set up a team early in 1993 under Shoemaker to plan the scientific exploitation of data from the craft, which has been built by the Naval Research Laboratory in Washington.

Unlike previous DoD or NASA spacecraft, Clementine uses advanced electronics and optics technology already used in devices such as camcorders and portable computers. The sensors designed for Clementine by the Lawrence Livermore laboratory in California use little power, and weigh less than a kilogram.

Not all planetary scientists are happy, however, about riding on Star Wars' coat tails. They are concerned less about the morality of the Star Wars programme itself - an old controversy that has been largely defused by historical events - than the impact of Clementine on the prospects for 'real' scientific missions both to asteroids and to the Moon.

"Many scientists are at least uneasy about working with military programmes in space," says Clark Chapman of the Planetary Science Institute, a division of the research company SAIC based in Tuscon, Arizona. But Chapman says that he shares more specific concerns about Clementine with a sizeable faction of planetary scientists.

"The approach that has been used definitely makes science a second-class citizen," Chapman says. "The threat is that it will be decided that this is the right way to do business: quick, cheap [space vehicles] using off-the-shelf instruments and perhaps not returning much science."

Supporters of Clementine point out that NASA is already funding at least one 'real' asteroid mission, the Near Earth Asteroid Rendezvous (NEAR) which is under construction at Johns Hopkins University in Maryland, and will be launched to the asteroid Eros in 1996.

These scientists say that the critics of Clementine are allowing their political view of Star Wars to colour their judgement. "It's a good idea, and one which will hardly cost NASA anything," says Jeffrey Bell, an asteroid astronomer at the University of Hawaii. "Why turn down a free lunch?"

But the critics, who had previously been worried that Clementine's existence might jeopardize NEAR, are now fretting about

the future. These two missions will provide information about the surface appearance of asteroids: data about craters, for example, will help astronomers to develop models showing how many rocks may be flying around in the Solar System.

Geologists, however, want to study rock samples returned from asteroids. They worry that Clementine may delay the day they get them, because a number of smaller missions could delay the launch of a larger mission.

Such worries are probably unfounded. Clementine is primarily an engineering, not a science, mission. Experience from it will help make future missions cheaper, smaller and quicker. And the ceilings being proposed on future NASA mission costs should ensure that more probes are sent to nearEarth asteroids and the Moon, as the agency will not be able to afford to go much further afield.

Colin Macilwain

\section{Hubble success boosts NASA's star}

Washington. A delighted Hubble Space Telescope science team released the first images from the repaired telescope last week, declaring, in the words of Ed Weiler, a programme scientist, that "the Hubble is fixed beyond our wildest expectations".

Ever since taking a first look at images from the corrected telescope in late December, astronomers say they have been amazed at how well the repairs appear to have worked. Earlier in the month, astronauts working from the shuttle had replaced the telescope's Wide Field/Planetary Camera (WFPC), installed a system of mirrors called COSTAR that restores three other instruments to near-full capability, replaced solar panels and gyroscopes, and upgraded computers.

Project managers had thought they would need until late January to calibrate and adjust the newly installed instruments from the ground. But the work went faster than expected. "We've had to devote no time whatsoever to troubleshooting," says David Leckrone of the National Aeronautics and Space Administration's Goddard Space Flight Center.

Leckrone says that the handling of the instruments by the astronauts in space had been so "benign, even gentle", that the instruments were barely knocked out of their pre-launch alignment.

Two onboard spectrographs are still being adjusted. But the Hubble team is confident that they, too, have been restored to full working order. "We clearly nailed the prescription," says Weiler. Some scientific investigations with the telescope are beginning this week, and it should be back to a regular schedule of observations by mid-February.

Team scientists say that the new WFPC images are twice as detailed as any images they could have obtained before the repair, even with computer processing to remove the effects of the flawed mirror.

Some 1,200-1,500 astronomers are waiting to use the telescope now that it has been fixed. Early priorities include spectrographic searches for evidence of black holes and searches for evidence of planets around other stars.

On the basis of the performance of the repaired telescope, scientists also are confident that they will be able to determine the rate of expansion of the Universe to an accuracy of 10 per cent.

The scientists and engineers who designed and built Hubble feel that their efforts have finally been vindicated by the new results after three and a half frustrating years. Indeed, Senator Barbara Mikulski (Democrat, Maryland), who oversees the congressional committee that funds NASA, used the occasion to declare that the space agency has shown its "right stuff" by fixing the telescope on time and on budget.

Mikulski also said that the repair will raise confidence in Congress that an orbiting space station can be successfully built and operated. Astronomers would probably prefer that any political goodwill from Hubble's triumph translates into support for two other planned space observatories - the Advanced X-Ray Astrophysics Facility (AXAF) and the Space Infrared Telescope Facility (SIRTF) - both of which face tough funding battles.

Tony Reichhardt 